\title{
Renal impact of high-loading-dose statin pre-cardiac catheterization in patients with chronic kidney disease and long-term statin use
}

\author{
CHANG HOU, BO ZHENG, XIN-GANG WANG, BIN ZHANG, QIU-PING SHI and MING CHEN \\ Department of Cardiology, Peking University First Hospital, Beijing 100034, P.R. China
}

Received September 27, 2018; Accepted May 23, 2019

DOI: $10.3892 /$ etm.2019.7766

\begin{abstract}
Previous studies have reported that short-term statin loading effectively protects statin-naive patients with mild renal insufficiency from contrast-induced acute kidney injury (CI-AKI). The aim of the present study was to determine whether patients with more advanced chronic kidney disease (CKD) and long-term statin therapy also benefit from high-loading statin pretreatment. A total of 256 consecutive patients with moderate-to-severe CKD receiving long-term statin therapy and undergoing percutaneous coronary intervention (PCI) or coronary artery angiography (CAG) were divided into the statin-loading group $(n=34)$ and the no statin-loading group $(n=222)$, depending on whether the respective patient received high-dose statin within $24 \mathrm{~h}$ prior to the intervention. The primary endpoint was the percent change in serum creatinine ( $\mathrm{SCr}$ ) levels. Additional endpoints included absolute change in SCr levels, estimated glomerular filtration rate (eGFR) at 48-72 h after contrast exposure, incidence rate of CI-AKI and composite in-hospital adverse events. The mean SCr decreased from baseline in either of the two groups, and the differences in the percent $(\mathrm{P}=0.930)$ and absolute change $(\mathrm{P}=0.990)$ in $\mathrm{SCr}$ levels were not significant between the two groups. Furthermore, no significant difference in the post-procedural eGFR was observed between the two groups. The incidence rates of CI-AKI (2.9 vs. 4.1\%, P>0.999) and in-hospital adverse events ( 0.0 vs. $3.6 \%, \mathrm{P}=0.602)$ were also similar between the two groups. Stratified analyses were then performed, which yielded results consistent with the above. Multiple linear regression indicated that the baseline eGFR value and current smoking status were independent factors affecting the post-procedural eGFR value, while high-dose statin
\end{abstract}

Correspondence to: Dr Ming Chen, Department of Cardiology, Peking University First Hospital, 8 Xishiku Street, Xicheng, Beijing 100034, P.R. China

E-mail: cm6141@sina.com

Key words: high-dose statin reload, contrast-induced acute kidney injury, chronic kidney disease, percutaneous coronary intervention, coronary angiography loading was not. Therefore, statin reloading prior to intervention may not provide any further renal protection or decrease the occurrence of in-hospital adverse events in patients with moderate-to-severe CKD receiving long-term statin therapy, which warrants validation in prospective trials.

\section{Introduction}

With the increasing demand in diagnostic and therapeutic cardiovascular interventions, the major concern regarding the use of contrast medium (CM) is the deterioration of renal function referred to as contrast-induced acute kidney injury (CI-AKI). Nash et al (1) reported CI-AKI as the third leading cause of hospital-acquired acute renal failure, accounting for $11 \%$ of all cases. The incidence of CI-AKI varies considerably, depending on the patient population studied $(2,3)$. As the baseline renal function worsens, there is a sharp increase in the rate of CI-AKI, and up to $26.6 \%$ of patients with severe pre-existing chronic kidney disease (CKD) are at risk of developing CI-AKI (4). CI-AKI resolves spontaneously in most cases, although transient dialysis may occasionally be required. Approximately $18.6 \%$ of patients with moderate-to-severe CKD who develop CI-AKI progress to irreversible renal dysfunction, leading to prolonged hospital stay, elevated medical costs, poor long-term clinical outcome and increased risk of death, persistent dialysis or major adverse cardiovascular events $(5,6)$. However, at present, no definitive treatment is available for this complication (7).

Statins are known to possess pleiotropic effects (anti-oxidant, anti-inflammatory and anti-thrombotic), independently of their intended effects on blood cholesterol levels $(8,9)$. Statins also improve endothelial function (10), increase nitric oxide bioavailability (11), prevent CM-induced renal tubular epithelial cell apoptosis, restore survival signaling pathways (12) and reduce the uptake of iodinated CM from the urinary space (13), which may counteract the specific pathophysiological mechanisms underlying CI-AKI and exert renoprotective effects. Although several clinical trials have indicated that short-term high-loading-dose statin administration correlates with a significant reduction in the incidence of CI-AKI, and a recent Bayesian network meta-analysis comparing the relative efficacy of multiple pharmacological interventions concluded that high-dose statins plus hydration may be the most effective strategy for the prevention of 
CI-AKI $(12,14-20)$. These previous studies mainly focused on statin-naive patients, while frequently excluding patients with severe renal impairment.

In the real-world setting, patients diagnosed with coronary artery disease always receive long-term statin therapy and occasionally develop advanced CKD. Thus, the aim of the present study was to examine the effect of high-dose statin reload on renal function among patients with moderate-to-severe CKD and long-term statin use undergoing percutaneous coronary intervention (PCI) or coronary artery angiography (CAG).

\section{Materials and methods}

Study population. The present study was a single-center retrospective clinical trial performed at Peking University First Hospital (Beijing, China). Consecutive patients with stage-3 or $-4 \mathrm{CKD}$ on long-term statin treatment who were identified through a medical history review and underwent scheduled PCI or CAG between January 2012 and December 2015 were enrolled. The exclusion criteria were stage-1 or $-2 \mathrm{CKD}$, end-stage renal disease (ESRD) requiring hemodialysis or peritoneal dialysis, other causes of AKI prior to catheterization, unavailable serum creatinine ( $\mathrm{SCr}$ ) value 48-72 $\mathrm{h}$ after the procedure or missing data on CM dosage, acute ST-segment elevation myocardial infarction (STEMI), cardiogenic shock or hemodynamic instability, and administration of iodinated $\mathrm{CM}$ during the week preceding the procedure. Eligible patients were then assigned to the statin-loading group and the no statin-loading group, according to whether they were administered high-dose statins (atorvastatin $\geq 40 \mathrm{mg}$ or rosuvastatin $\geq 10 \mathrm{mg}$ ) within $24 \mathrm{~h}$ prior to the procedure.

Study protocol. The angiographic reports saved in the Innova IGS 520 (GE Medical Systems SCS) and the corresponding medical records of the patients were retrieved and reviewed. The demographic data and medical history of the patients were recorded. The following clinical information was also documented: Final diagnosis, left ventricular ejection fraction (LVEF), category and dosage of chronically or pre-procedurally administered statins, baseline $\mathrm{SCr}$ and estimated glomerular filtration rate (eGFR), SCr peak level and eGFR value at 48-72 $\mathrm{h}$ after PCI or CAG, and occurrence of in-hospital adverse events, including dialysis, all-cause death, stent thrombosis, as well as cerebral infarction. The procedural characteristics, particularly preparatory hydration and type or volume of CM used, were recorded.

The eGFR values were calculated from baseline and peak post-procedural $\mathrm{SCr}$ concentrations using the CKD Epidemiology Collaboration equation for 'white and other', which illustrates the specific algorithm of eGFR (21). Renal function was classified according to the stages set by the National Kidney Foundation (USA) Kidney Disease Outcomes Quality Initiative as follows: Stage 1, CKD with eGFR $\geq 90 \mathrm{ml} / \mathrm{min} / 1.73 \mathrm{~m}^{2}$, considered normal; stage 2, CKD with eGFR $60-89 \mathrm{ml} / \mathrm{min} / 1.73 \mathrm{~m}^{2}$, considered mildly impaired; stage 3, CKD with eGFR 30-59 ml/min $/ 1.73 \mathrm{~m}^{2}$, considered moderately impaired; stage 4 , CKD with eGFR $15-29 \mathrm{ml} / \mathrm{min} / 1.73 \mathrm{~m}^{2}$, considered severely impaired; and stage 5, CKD with eGFR $<15 \mathrm{ml} / \mathrm{min} / 1.73 \mathrm{~m}^{2}$, considered ESRD (22).
Endpoints and definitions. Given the difference in baseline $\mathrm{SCr}$ levels between the two groups, the percent change of peri-procedural SCr levels was selected as the primary endpoint. Additional endpoints included the absolute value of $\mathrm{SCr}$ change, eGFR value at 48-72 $\mathrm{h}$ after PCI or CAG according to the CI-AKI definition, incidence rate of CI-AKI (defined as a SCr concentration increase by $\geq 0.5 \mathrm{mg} / \mathrm{dl}$ or $\geq 25 \%$ above baseline within 48-72 h after contrast exposure) (23) and composite in-hospital adverse events. The absolute difference in $\mathrm{SCr}$ levels was calculated as the baseline minus post-operative peak $\mathrm{SCr}$ concentration, while the percent change was the ratio of absolute change and baseline SCr concentration.

Non-ST-segment elevation acute coronary syndrome (NSTE-ACS) included unstable angina and non-STEMI. The contrast volume exceeding $140 \mathrm{ml}$ was considered as a high-dose CM load (24).

Statistical analysis. Statistical analysis was performed using SPSS version 19.0 (IBM Corp.). The Shapiro-Wilk test was used to examine the normality of distribution. Normally distributed continuous variables were expressed as the mean \pm standard deviation and analyzed using independent Student's t-tests. Non-normally distributed variables were presented as the median (interquartile range) and comparisons were performed using Mann-Whitney U-tests. All categorical data, expressed as absolute numbers (percentages) were compared between the two groups using Chi-squared or Fisher's exact tests. Stratified analyses were also performed in each pre-specified subgroup, and multiple linear regression was applied to adjust for age, sex, medical history and baseline differences in clinical and procedural factors. All statistical analyses were two-tailed. $\mathrm{P}<0.05$ was considered to indicate statistical significance.

\section{Results}

Patient population and baseline characteristics. A total of 256 patients were considered eligible for final analysis and were assigned to the statin-loading group $(n=34)$ or the no statin-loading group ( $n=222$; Fig. 1 ).

The mean age of the participants was $71.38 \pm 10.27$ years and $160(62.5 \%)$ were male. There were no significant differences with respect to age, sex, height, body mass index, medical history or LVEF between the statin-loading and no statin-loading groups $(\mathrm{P}>0.05)$. The baseline $\mathrm{SCr}$ level and the percentage of severe renal insufficiency were similar between the two groups ( $P>0.05)$. The baseline eGFR value was numerically lower in the statin-loading group, but the difference was not statistically significant $(\mathrm{P}=0.054)$. Compared with that in the no statin-loading group, the number of patients diagnosed with NSTE-ACS was significantly higher in the statin-loading group (97.1 vs. 83.3\%; $\mathrm{P}=0.036$ ). No significant difference was observed regarding the categories of statins chronically administered $(\mathrm{P}=0.255$ for atorvastatin and $\mathrm{P}=0.262$ for rosuvastatin; Table I).

The number of vessels with stenosis $\geq 50 \%$ and stents deployed, culprit vessels, as well as usage of glycoprotein IIb/IIIa inhibitors, were well-balanced $(\mathrm{P}>0.05)$. Of the 256 patients, $63.3 \%$ received peri-procedural hydration $(n=162)$, without any significant difference between the two groups (67.6 vs. $62.6 \%$; $\mathrm{P}=0.571)$. However, the volume of $\mathrm{CM}$ and the proportion of patients receiving high-dose $\mathrm{CM}$ were 


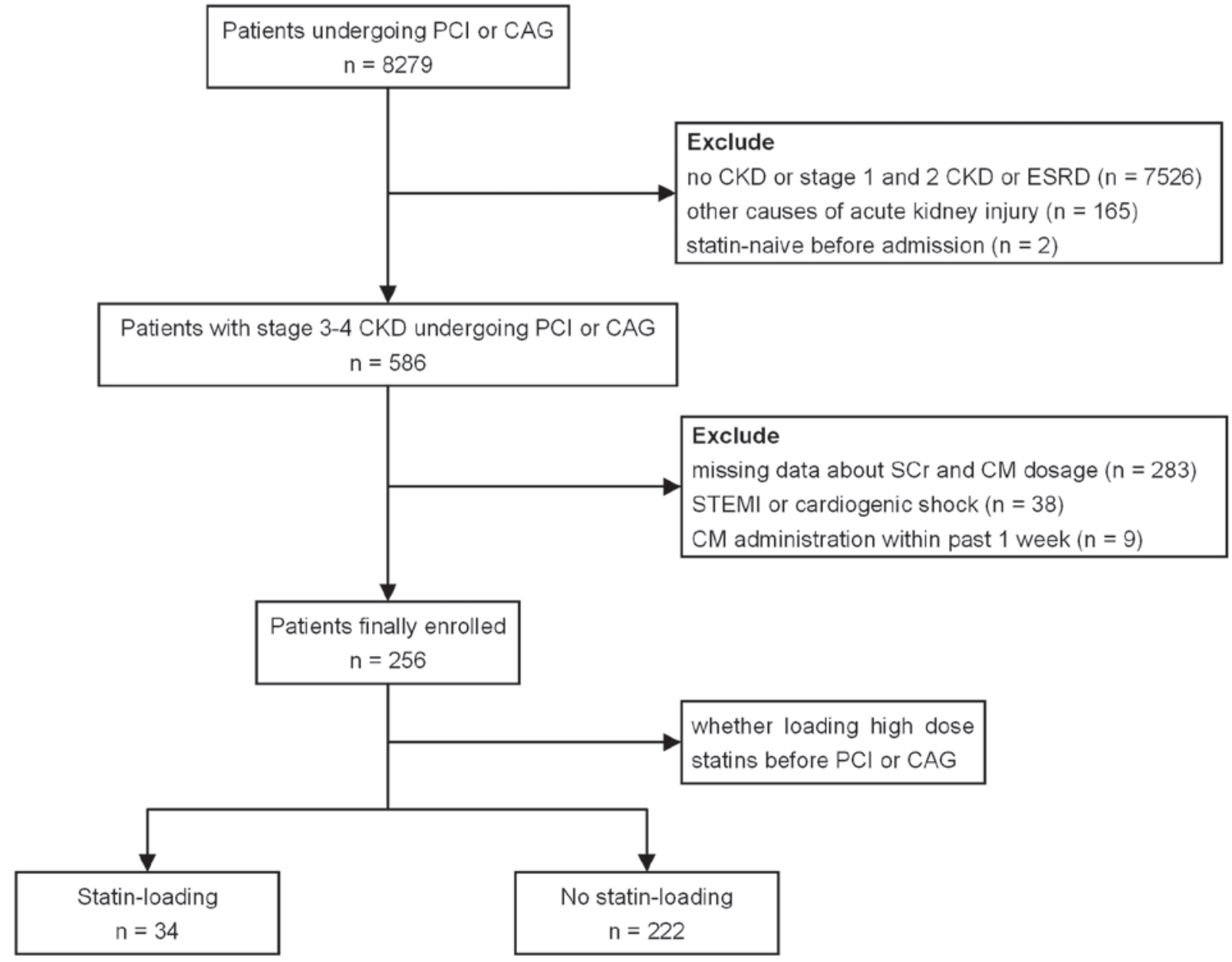

Figure 1. Study flowchart. CKD, chronic kidney disease; CAG, coronary artery angiography; PCI, percutaneous coronary intervention; ESRD, end-stage renal disease; SCr, serum creatinine; CM, contrast medium; STEMI, ST-segment elevation myocardial infarction.

significantly decreased in the statin-loading group $(\mathrm{P}=0.025$ and $\mathrm{P}=0.017$, respectively). In the statin-loading group, a markedly higher proportion of patients was exposed to iso-osmolar iodixanol than that in the no statin-loading group (52.9 vs. 23.9\%; P<0.001; Table I).

Changes in renalfunction parameters. The normal range of $\mathrm{SCr}$ is $59-104 \mu \mathrm{mol} / 1$ for males and $45-84 \mu \mathrm{mol} / 1$ for females (25). A decrease in post-procedural peak $\mathrm{SCr}$ levels in either of the two groups was observed, while the percent change in the $\mathrm{SCr}$ concentration was not significantly different between the two groups $(0.91 \pm 13.81$ vs. $0.71 \pm 12.11 \%$; $\mathrm{P}=0.930$; Fig. 2$)$. There was also no significant difference in the absolute $\mathrm{SCr}$ change $(1.10 \pm 20.33$ vs. $1.06 \pm 17.27 \mu \mathrm{mol} / \mathrm{l} ; \mathrm{P}=0.990$; Fig. 2$)$. The eGFR value at $48-72 \mathrm{~h}$ after PCI or CAG was above baseline and comparable between the two groups $(\mathrm{P}=0.119$; Table II). The baseline and post-procedural SCr levels were slightly higher in the statin-loading group compared with those in the no statin-loading group $(\mathrm{P}=0.208$ and $\mathrm{P}=0.252$; Table II).

Incidence of CI-AKI. One patient (2.9\%) in the statin-loading group and 9 patients $(4.1 \%)$ in the no statin-loading group developed CI-AKI within 48-72 h of CM administration. The CI-AKI rate was similar between the two groups ( $\mathrm{P}>0.999$, Fisher's exact test; Fig. 3 and Table III).
In-hospital clinical outcome. No deaths were reported in either group. No dialysis, stent thrombosis or cerebral infarction occurred in the statin-loading group, whereas the corresponding incidence of dialysis, stent thrombosis and cerebral infarction in the no statin-loading group was 2.3, 0.9 and $0.5 \%$, respectively. There was no significant difference in the in-hospital composite adverse events of all-cause death, dialysis, stent thrombosis and cerebral infarction after CM exposure (0.0 vs. $3.6 \%$; $\mathrm{P}=0.602$, Fisher's exact test; Table III).

Subgroup analyses. Stratified analyses according to the presence of severe renal functional impairment, concomitant diabetes mellitus, adequate hydration, administration of high-dose CM, selection of an iso-osmolar CM and advanced age ( $\geq 75$ years) demonstrated consistent results when the statin-loading and no statin-loading groups were compared. Of note, in the high-dose CM and elderly patient subgroups, the eGFR value post-procedure was significantly lower in the statin-loading group compared with that in the no statin-loading group $(\mathrm{P}=0.034$ and $\mathrm{P}=0.043$, respectively; Table IV).

Multiple linear regression. The analysis revealed that a low baseline eGFR value $(\beta=0.911, \mathrm{P}<0.001)$ and current smoking status (smokers vs. non-smokers: $\beta=-2.469, \mathrm{P}=0.019$ ) were significantly associated with a reduction in the eGFR 
Table I. Baseline characteristics of patients.

\begin{tabular}{|c|c|c|c|}
\hline \multirow[b]{2}{*}{ Characteristic } & \multirow{2}{*}{$\frac{\text { Statin-loading group }}{(n=34)}$} & \multirow{2}{*}{$\frac{\text { No-statin loading group }}{(n=222)}$} & \multirow[b]{2}{*}{ P-value } \\
\hline & & & \\
\hline Age (years) & $70.41 \pm 11.89$ & $71.52 \pm 10.02$ & 0.558 \\
\hline Male & $23(67.6)$ & 137 (61.7) & 0.506 \\
\hline Height (cm) & $165(158.75-171.25)$ & $165(160.00-171.00)$ & 0.677 \\
\hline BMI $\left(\mathrm{kg} / \mathrm{m}^{2}\right)$ & $27.01 \pm 5.13$ & $26.00 \pm 3.51$ & 0.297 \\
\hline Diabetes mellitus & $15(44.1)$ & $100(45.0)$ & 0.919 \\
\hline Hypertension & $28(82.4)$ & $195(87.8)$ & 0.408 \\
\hline Hyperlipidemia & $25(73.5)$ & $144(64.9)$ & 0.321 \\
\hline Current smoking & $10(29.4)$ & $60(27.0)$ & 0.771 \\
\hline Previous PCI & $14(41.2)$ & $88(39.6)$ & 0.865 \\
\hline Previous CABG & $1(2.9)$ & $9(4.1)$ & $>0.999$ \\
\hline Previous MI & $9(26.5)$ & $60(27.0)$ & 0.946 \\
\hline $\operatorname{LVEF}(\%)$ & $60.48 \pm 16.61$ & $65.39 \pm 12.75$ & 0.118 \\
\hline \multicolumn{4}{|l|}{ Cardiac presentation } \\
\hline SCAD & $1(2.9)$ & $37(16.7)$ & 0.036 \\
\hline NSTE-ACS & $33(97.1)$ & $185(83.3)$ & 0.036 \\
\hline Baseline $\mathrm{SCr}(\mu \mathrm{mol} / \mathrm{l})$ & $139.41 \pm 33.80$ & $129.82 \pm 42.27$ & 0.208 \\
\hline Baseline eGFR (ml/min/1.73 m²) & $42.27 \pm 9.45$ & $46.08 \pm 10.87$ & 0.054 \\
\hline Severe CKD & $4(11.8)$ & $21(9.5)$ & 0.755 \\
\hline \multicolumn{4}{|l|}{ Chronic statins administered } \\
\hline Atorvastatin & $29(85.3)$ & $170(76.6)$ & 0.255 \\
\hline Rosuvastatin & $4(11.8)$ & $44(19.8)$ & 0.262 \\
\hline Number of $\geq 50 \%$ stenotic vessels & $2.24 \pm 0.96$ & $2.18 \pm 0.93$ & 0.750 \\
\hline \multicolumn{4}{|l|}{ Culprit vessel } \\
\hline LAD & $29(85.3)$ & $184(82.9)$ & 0.726 \\
\hline $\mathrm{LCX}$ & $20(58.8)$ & $135(60.8)$ & 0.825 \\
\hline $\mathrm{RCA}$ & $23(67.6)$ & $145(65.3)$ & 0.790 \\
\hline LM & $4(11.8)$ & $16(7.2)$ & 0.317 \\
\hline Graft vessel & $0(0.0)$ & $4(1.8)$ & $>0.999$ \\
\hline Number of stents & $1.50 \pm 0.83$ & $1.72 \pm 1.04$ & 0.238 \\
\hline PCI & $31(91.2)$ & $206(92.8)$ & 0.725 \\
\hline GPI administration & $7(20.6)$ & $80(36.0)$ & 0.077 \\
\hline Hydration & $23(67.6)$ & 139 (62.6) & 0.571 \\
\hline \multicolumn{4}{|l|}{ CM type } \\
\hline Iohexol & $4(11.8)$ & $57(25.7)$ & 0.076 \\
\hline Iodixanol & $18(52.9)$ & $53(23.9)$ & $<0.001$ \\
\hline Iopamidol & $7(20.6)$ & $65(29.3)$ & 0.294 \\
\hline Iopromide & $5(14.7)$ & $47(21.2)$ & 0.383 \\
\hline CM dose (ml) & $129.85 \pm 37.39$ & $151.23 \pm 53.08$ & 0.025 \\
\hline High-dose CM load & $13(38.2)$ & 133 (59.9) & 0.017 \\
\hline
\end{tabular}

value at 48-72 h after PCI or CAG, after adjusting for age, sex, medical history, and baseline heterogeneities in clinical and procedural factors. By contrast, high-dose statin reload exerted no significant effect on the post-procedural eGFR value $(\mathrm{P}=0.618$; Table $\mathrm{V})$. The 'constant' $\beta_{0}$ in the equation represents the potentially significant influencing factors of the 
Table II. Changes in renal function after administration of CM.

\begin{tabular}{|c|c|c|c|}
\hline & Statin-loading group & No statin-loading group & \\
\hline Renal function parameters & $(n=34)$ & $(\mathrm{n}=222)$ & P-value \\
\hline \multicolumn{4}{|l|}{$\mathrm{eGFR}^{\mathrm{a}}\left(\mathrm{ml} / \mathrm{min} / 1.73 \mathrm{~m}^{2}\right)$} \\
\hline Baseline & $42.27 \pm 9.45$ & $46.08 \pm 10.87$ & 0.054 \\
\hline Post procedure (48-72 h) & $43.69 \pm 11.35$ & $47.26 \pm 12.54$ & 0.119 \\
\hline \multicolumn{4}{|l|}{$\mathrm{SCr}^{\mathrm{b}}(\mu \mathrm{mol} / \mathrm{l})$} \\
\hline Baseline & $139.41 \pm 33.80$ & $129.82 \pm 42.27$ & 0.208 \\
\hline Post procedure (48-72 h) & $138.32 \pm 40.48$ & $128.77 \pm 45.78$ & 0.252 \\
\hline
\end{tabular}

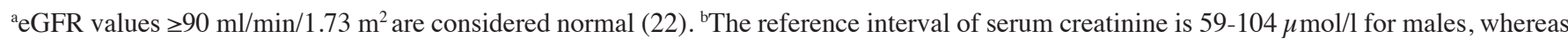
45-84 $\mu \mathrm{mol} / 1$ for females (25). eGFR, estimated glomerular filtration rate; $\mathrm{SCr}$, serum creatinine.
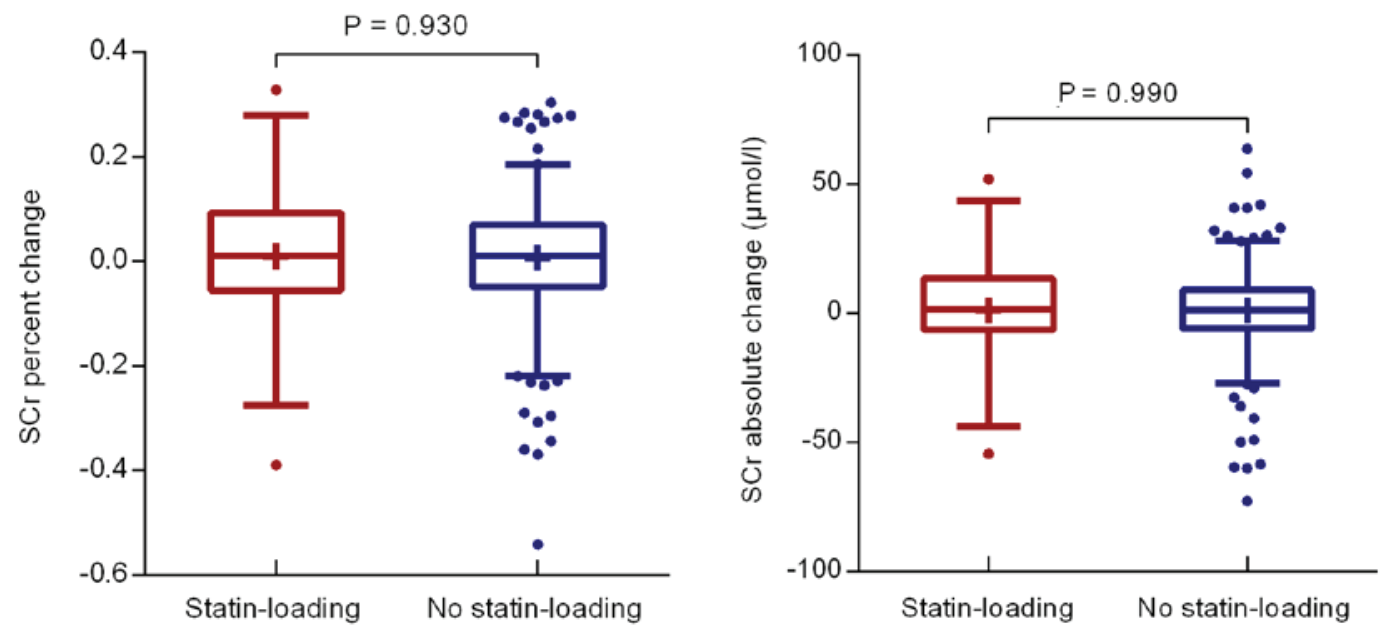

Figure 2. Percent and absolute change in peri-procedural SCr concentration. The SCr peak value at $48-72 \mathrm{~h}$ after percutaneous coronary intervention or coronary artery angiography in the two groups exhibited a decrease from baseline. However, there were no significant differences in percent $(\mathrm{P}=0.930)$ or absolute change $(\mathrm{P}=0.990)$ in $\mathrm{SCr}$ levels between the statin-loading and no statin-loading groups. SCr, serum creatinine.

post-procedural eGFR value not included as an independent variable $(\mathrm{P}<0.001$; Table V).

\section{Discussion}

Several clinical trials have been designed to evaluate the efficacy of statins in the prevention of CI-AKI, with controversial results. Furthermore, only few studies have investigated the renoprotective role of statin reload in patients with moderate-to-severe CKD receiving long-term statin therapy who undergo cardiac catheterization (12,14-19,26-29). The major results of the present study indicate that, compared with no statin loading, high-dose statin pre-treatment does not further protect renal function, reduce the occurrence of CI-AKI or improve in-hospital clinical outcome for such patients.

An eGFR of $<60 \mathrm{ml} / \mathrm{min} / 1.73 \mathrm{~m}^{2}$ is currently generally accepted as the threshold for risk of CI-AKI (30). Certain retrospective and observational trials indicated that prophylactic administration of statins prior to catheterization may be associated with lower risk of CI-AKI among CKD patients, and this early benefit translated into shorter hospital

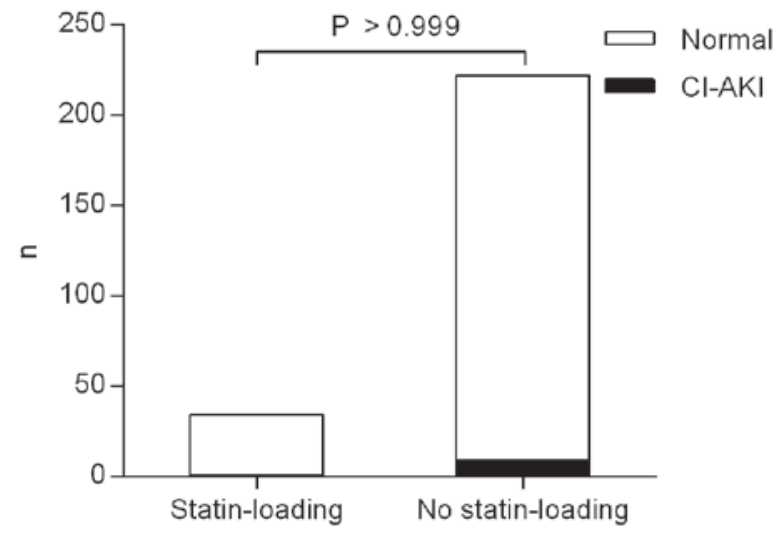

Figure 3. CI-AKI occurrence. The incidence rate of CI-AKI was comparable between the statin-loading and no statin-loading groups 2.9 vs. $4.1 \%$, $\mathrm{P}>0.999$; Fisher's exact test. CI-AKI, contrast-induced acute kidney injury.

stay, along with improved long-term clinical outcome (31-34). Certain prospective, randomized and controlled trials also investigated whether peri-procedural high-dose statins efficiently protect the renal function of CKD patients. 
Table III. CI-AKI occurrence and in-hospital adverse events.

\begin{tabular}{|c|c|c|c|}
\hline & Statin-loading group & No statin-loading group & \\
\hline In-hospital adverse event & $(\mathrm{n}=34)$ & $(\mathrm{n}=222)$ & P-value \\
\hline CI-AKI & $1(2.9)$ & $9(4.1)$ & $>0.999$ \\
\hline Dialysis & $0(0.0)$ & $5(2.3)$ & - \\
\hline Death & $0(0.0)$ & $0(0.0)$ & - \\
\hline Stent thrombosis & $0(0.0)$ & $2(0.9)$ & - \\
\hline Cerebral infarction & $0(0.0)$ & $1(0.5)$ & - \\
\hline Composite endpoint & $0(0.0)$ & $8(3.6)$ & 0.602 \\
\hline
\end{tabular}

Values are expressed as n (\%). CI-AKI, contrast-induced acute kidney injury.

Quintavalle et al (12) reported that $80 \mathrm{mg}$ atorvastatin load within $24 \mathrm{~h}$ prior to $\mathrm{CM}$ exposure significantly reduced the incidence rate of CI-AKI in patients with moderate CKD undergoing PCI or CAG. Shehata and Hamza (14) investigated diabetic patients with mild-to-moderate renal impairment, and observed that the incidence of CI-AKI was lower among patients receiving atorvastatin $80 \mathrm{mg}$ daily for $48 \mathrm{~h}$ prior to elective PCI. The TRACK-D trial, including 2,998 Chinese patients with type 2 diabetes mellitus coincident with mild-to-moderate CKD who underwent coronary or peripheral arterial angiography, demonstrated that short-term high-dose rosuvastatin lowered the rate of CI-AKI and worsening heart failure during a 30-day follow-up (15). Recently, a network meta-analysis, including 150 trials with 31,631 participants that synchronously assessed different treatments, reported that high-dose statins plus hydration may be regarded as the best strategy to prevent CI-AKI (20). Accordingly, in the present study, high-loading-dose statins were generally prescribed for higher-risk patients with lower baseline eGFR values.

In line with the results of the present study, peri-procedural high-dose simvastatin administration in patients with renal insufficiency undergoing CAG was not associated with any differences in the mean peak increase of $\mathrm{SCr}$, incidence of CI-AKI, length of hospital stay or short-term clinical outcome in the PROMISS trial (35). Similarly, Toso et al (36) performed a prospective, single-center study on CKD patients, revealing that the mean increase in $\mathrm{SCr}$, CI-AKI rate, in-hospital mortality and requirement for dialysis did not significantly differ between the high-dose atorvastatin and placebo groups. Consistent results were reported in all of the prospectively defined higher-risk subgroups (36). However, unlike those in the present study, one of the enrollment criteria in the PROMISS trial included normal or only mildly impaired renal function (baseline $\mathrm{SCr} \geq 1.1 \mathrm{mg} / \mathrm{dl}$ ). More importantly, recent statin users were excluded from all of the above-mentioned trials. By contrast, the present study included patients on chronic statin administration with coexisting moderate-to-severe CKD.

Acikel et al (19) compared the efficacy of short-term and long-term statin therapy for CI-AKI prevention. They demonstrated that the $\mathrm{SCr}$ and eGFR values at $48 \mathrm{~h}$ after elective CAG were significantly better in the high-dose atorvastatin and chronic statin therapy groups compared with those in control subjects, whereas no differences were observed in renal function parameters between the high-dose and chronic statin therapy groups. While certain results of the above study were similar to those of the present study, in terms of the comparable benefits of the two statin regimens, the discrepancy in the inclusion criteria of the two studies is noteworthy. Acikel et al (19) excluded patients with a moderate-to-severe decrease in eGFR, while the present study focused on a patient population with moderate-to-severe CKD.

In the NAPLES II trial, $80 \mathrm{mg}$ atorvastatin load prior to CM exposure failed to lower the CI-AKI rate in the subgroup with severe CKD (12). Patti et al (33) also observed that patients treated with a variety of statins undergoing PCI exhibited a $90 \%$ risk reduction of CI-AKI, apart from those with a creatinine clearance $<40 \mathrm{ml} / \mathrm{min}$, possibly due to the multiple irreversible pathogenetic mechanisms underlying the development of advanced renal failure $(33,37)$. One meta-analysis of 31 prospective randomized trials reported that the effect of statin therapy on renal outcome was markedly affected by kidney function, and the relative effect was significantly reduced in patients with more advanced kidney dysfunction (38). Since the majority of the patients analyzed in the present study had moderate-to-severe CKD, with severe CKD accounting for $\sim 10 \%$ of the cases, it is reasonable to hypothesize that the beneficial effects of high-loading-dose statins on renal function are offset. This may also partly explain the significantly lower post-procedural eGFR values in the higher-risk statin-loading group observed in the high-dose CM and elderly patient subgroup analyses, despite the application of various precautionary strategies.

Lower creatinine clearance is associated with a higher frequency of death or myocardial infarction during the initial hospital stay and at 1 year among patients with CKD undergoing PCI. Furthermore, during the initial hospital stay, a stepwise increase in hemorrhagic complications with declining creatinine clearance is observed (39). The results of two previous large registry cohorts demonstrated that prescription of statins correlated with a significant improvement in subsequent outcomes, including death and composite endpoints of death, myocardial infarction and target vessel revascularization in the mild CKD stratum $(40,41)$. According to the 
Table IV. Subgroup analyses of differences in study endpoints.

\begin{tabular}{|c|c|c|c|}
\hline Subgroup & Statin-loading & No statin-loading & P-value \\
\hline \multicolumn{4}{|l|}{ eGFR $\left(\mathrm{ml} / \mathrm{min} / 1.73 \mathrm{~m}^{2}\right)$} \\
\hline \multicolumn{4}{|l|}{$<30$} \\
\hline Number of patients & 4 & 21 & \\
\hline Change in $\mathrm{SCr}(\%)$ & $-7.08 \pm 8.31$ & $3.84 \pm 12.44$ & 0.108 \\
\hline Post-procedure eGFR & $25.19 \pm 1.27$ & $25.42 \pm 6.62$ & 0.947 \\
\hline CI-AKI & $0(0)$ & $2(9.5)$ & $>0.999$ \\
\hline \multicolumn{4}{|l|}{$\geq 30$} \\
\hline Number of patients & 30 & 201 & \\
\hline Change in $\mathrm{SCr}(\%)$ & $1.97 \pm 14.14$ & $0.38 \pm 12.06$ & 0.510 \\
\hline Post-procedure eGFR & $46.15 \pm 9.64$ & $49.54 \pm 10.68$ & 0.103 \\
\hline CI-AKI & $1(3.3)$ & $7(3.5)$ & $>0.999$ \\
\hline \multicolumn{4}{|l|}{ Diabetes } \\
\hline \multicolumn{4}{|l|}{ Yes } \\
\hline Number of patients & 15 & 100 & \\
\hline Change in $\mathrm{SCr}(\%)$ & $-3.44 \pm 10.38$ & $0.15 \pm 12.38$ & 0.289 \\
\hline Post-procedure eGFR & $39.93 \pm 9.92$ & $45.47 \pm 13.69$ & 0.069 \\
\hline CI-AKI & $0(0)$ & $5(5)$ & $>0.999$ \\
\hline \multicolumn{4}{|l|}{ No } \\
\hline Number of patients & 19 & 122 & \\
\hline Change in $\mathrm{SCr}(\%)$ & $4.34 \pm 15.42$ & $1.17 \pm 11.91$ & 0.302 \\
\hline Post-procedure eGFR & $46.66 \pm 11.77$ & $48.73 \pm 11.37$ & 0.463 \\
\hline CI-AKI & $1(5.3)$ & $4(3.3)$ & 0.520 \\
\hline \multicolumn{4}{|l|}{ Hydration } \\
\hline \multicolumn{4}{|l|}{ Yes } \\
\hline Number of patients & 23 & 139 & \\
\hline Change in $\mathrm{SCr}(\%)$ & $-1.61 \pm 14.71$ & $0.16 \pm 12.53$ & 0.543 \\
\hline Post-procedure eGFR & $40.32 \pm 9.66$ & $43.98 \pm 12.61$ & 0.117 \\
\hline CI-AKI & $1(4.3)$ & $7(5.0)$ & $>0.999$ \\
\hline \multicolumn{4}{|l|}{ No } \\
\hline Number of patients & 11 & 83 & \\
\hline Change in $\mathrm{SCr}(\%)$ & $6.17 \pm 10.42$ & $1.63 \pm 11.38$ & 0.213 \\
\hline Post-procedure eGFR & $50.74 \pm 11.80$ & $52.75 \pm 10.38$ & 0.554 \\
\hline CI-AKI & $0(0)$ & $2(2.4)$ & $>0.999$ \\
\hline \multicolumn{4}{|l|}{ CM dose (ml) } \\
\hline \multicolumn{4}{|l|}{$\geq 140$} \\
\hline Number of patients & 13 & 133 & \\
\hline Change in $\mathrm{SCr}(\%)$ & $-2.84 \pm 13.78$ & $0.15 \pm 11.84$ & 0.393 \\
\hline Post-procedure eGFR & $39.96 \pm 9.85$ & $47.58 \pm 12.46$ & 0.034 \\
\hline CI-AKI & $1(7.7)$ & $6(4.5)$ & 0.487 \\
\hline \multicolumn{4}{|l|}{$<140$} \\
\hline Number of patients & 21 & 89 & \\
\hline Change in $\mathrm{SCr}(\%)$ & $3.23 \pm 13.64$ & $1.54 \pm 12.51$ & 0.585 \\
\hline Post-procedure eGFR & $45.99 \pm 11.82$ & $46.78 \pm 12.71$ & 0.796 \\
\hline CI-AKI & $0(0)$ & $3(3.4)$ & $>0.999$ \\
\hline \multicolumn{4}{|l|}{$\mathrm{CM}$} \\
\hline \multicolumn{4}{|l|}{ Iodixanol } \\
\hline Number of patients & 18 & 53 & \\
\hline Change in $\mathrm{SCr}(\%)$ & $-1.29 \pm 16.55$ & $-0.18 \pm 14.23$ & 0.784 \\
\hline Post-procedure eGFR & $40.90 \pm 12.05$ & $40.83 \pm 10.84$ & 0.981 \\
\hline CI-AKI & $1(5.6)$ & $2(3.8)$ & $>0.999$ \\
\hline
\end{tabular}


Table IV. Continued.

\begin{tabular}{|c|c|c|c|}
\hline Subgroup & Statin-loading & No statin-loading & P-value \\
\hline \multicolumn{4}{|l|}{ Other } \\
\hline Number of patients & 16 & 169 & \\
\hline Change in $\mathrm{SCr}(\%)$ & $3.39 \pm 9.85$ & $0.99 \pm 11.39$ & 0.417 \\
\hline Post-procedure eGFR & $46.83 \pm 9.95$ & $49.28 \pm 12.38$ & 0.444 \\
\hline CI-AKI & $0(0)$ & $7(4.1)$ & $>0.999$ \\
\hline \multicolumn{4}{|l|}{ Age (years) } \\
\hline \multicolumn{4}{|l|}{$\geq 75$} \\
\hline Number of patients & 16 & 97 & \\
\hline Change in $\mathrm{SCr}(\%)$ & $2.16 \pm 15.83$ & $-0.66 \pm 12.90$ & 0.436 \\
\hline Post-procedure eGFR & $40.29 \pm 11.35$ & $46.61 \pm 11.48$ & 0.043 \\
\hline CI-AKI & $1(6.3)$ & $5(5.2)$ & $>0.999$ \\
\hline \multicolumn{4}{|l|}{$<75$} \\
\hline Number of patients & 18 & 125 & \\
\hline Change in $\mathrm{SCr}(\%)$ & $-0.20 \pm 12.09$ & $1.77 \pm 11.40$ & 0.498 \\
\hline Post-procedure eGFR & $46.71 \pm 10.76$ & $47.76 \pm 13.33$ & 0.749 \\
\hline CI-AKI & $0(0)$ & $4(3.2)$ & $>0.999$ \\
\hline
\end{tabular}

Values are expressed as the mean \pm standard deviation or $\mathrm{n}(\%)$. CI-AKI, contrast-induced acute kidney injury; eGFR, estimated glomerular filtration rate; $\mathrm{SCr}$, serum creatinine; $\mathrm{CM}$, contrast medium.

Table V. Multivariate analysis for post-procedural eGFR value.

\begin{tabular}{|c|c|c|c|}
\hline Variable in model & $\begin{array}{l}\text { Partial regression } \\
\text { coefficient }\end{array}$ & t statistic & P-value \\
\hline Constant $\left(\beta_{0}\right)$ & 11.335 & 3.574 & $<0.001$ \\
\hline Statin loading & 0.650 & 0.499 & 0.618 \\
\hline Age $\geq 75$ years & -1.632 & -1.794 & 0.074 \\
\hline Male sex & 1.430 & 1.454 & 0.147 \\
\hline Diabetes mellitus & -0.969 & -1.086 & 0.279 \\
\hline Hypertension & -0.629 & -0.469 & 0.640 \\
\hline Hyperlipidemia & -0.965 & -1.031 & 0.304 \\
\hline Current smoking & -2.469 & -2.370 & 0.019 \\
\hline NSTE-ACS & -1.784 & -1.454 & 0.147 \\
\hline Baseline eGFR $^{\mathrm{a}}$ & 0.911 & 20.136 & $<0.001$ \\
\hline$\geq 2$ vessels diseased $^{b}$ & -0.478 & -0.495 & 0.621 \\
\hline Iodixanol administration & -1.912 & -1.852 & 0.065 \\
\hline High-dose CM load & -1.028 & -1.137 & 0.257 \\
\hline Adequate hydration & -1.682 & -1.698 & 0.091 \\
\hline
\end{tabular}

${ }^{a}$ Continuous variable. ${ }^{b}$ Including single left main lesion. eGFR, estimated glomerular filtration rate; CM, contrast medium; NSTE-ACS, non-ST-segment elevation acute coronary syndrome.

dyslipidemia management guidelines, patients diagnosed with ACS should receive moderate-to-high-intensity statin therapy for atherosclerotic cardiovascular disease as a secondary prevention $(42,43)$. The patient-centered approach proposed by the National Lipid Association Expert Panel recommends that patients with ACS or stage-3B-4 CKD are classified as very high- or high-risk and, therefore, high-intensity statin therapy should be considered (44). The updated European Clinical Practice Guidelines also recommend that high-intensity statin therapy should be initiated as early as possible in recently diagnosed ACS or CKD patients (45). On the basis of this evidence, long-term statin administration must be advocated in CKD patients and those diagnosed with NSTE-ACS, as in the present study.

Distinct from previous studies, the peak SCr values within 48-72 $\mathrm{h}$ post-PCI or -CAG declined in the two groups of the present study, and the CI-AKI rate was merely $3.9 \%$, which is notably lower compared with that reported in the literature; these results may be attributed to the sufficient preventive measures. The principles of CI-AKI prevention and management include using as low as reasonably achievable volumes of CM, selecting the least toxic iodinated CM, and hydration with isotonic crystalloid solution $12 \mathrm{~h}$ prior to and at least $24 \mathrm{~h}$ after the procedure (46-48). Thus, in the present study, in addition to statin administration, $63.3 \%$ of the patients received adequate hydration. Furthermore, the mean CM dosage $(129.85 \pm 37.39$ vs. $151.23 \pm 53.08 \mathrm{ml} ; \mathrm{P}=0.025)$ was markedly lower and the proportion of iso-osmolar iodixanol use was higher in patients with lower baseline eGFR values.

There are several limitations to the present study. First, due to the retrospective design and lack of randomization, there was significant heterogeneity with respect to baseline clinical or procedural variables between the two groups, and a causal association cannot be verified from the present analyses. Second, the eligible patients in the statin-loading group were relatively few, and only a small proportion of patients developed in-hospital adverse events, making this trial underpowered and possibly inconclusive. Third, the enrolled patients were followed up for only $48-72 \mathrm{~h}$, and the peak in 
$\mathrm{SCr}$ levels may have been missed. However, the majority of the patients developing CI-AKI experience an increase in $\mathrm{SCr}>0.5 \mathrm{mg} / \mathrm{dl}$ within $24 \mathrm{~h}$ after CM exposure (49); hence, the $\mathrm{SCr}$ peak may have been missed in only a small number of cases. Although all the patients included in the present study were administered statins chronically, the definitive duration of statin treatment remains undetermined. Next, the endpoints of the present study were limited to in-hospital events; consequently, the impact of high-loading-dose statins on the medium- or long-term clinical outcome and permanent functional state of the kidney was not evaluated. In addition, the present study only used SCr or eGFR values to reflect renal function, whereas the levels of serum cystatin $\mathrm{C}$, a more sensitive and reliable renal injury biomarker allowing an early diagnosis of CI-AKI (50), were not determined. Finally, the present study provided no information on the lipid profile of the patients, changes in the highly sensitive $\mathrm{C}$-reactive protein levels or monitoring of statin-associated adverse effects.

In conclusion, routine short treatment with high-dose atorvastatin or rosuvastatin on the background of chronic therapy prior to cardiac catheterization confers no added benefit to the renal function of patients with moderate-to-severe CKD or a reduction of the risk of in-hospital adverse events. These results require confirmation in further prospective and multi-center clinical trials.

\section{Acknowledgements}

Not applicable.

\section{Funding}

No funding was received.

\section{Availability of data and material}

The datasets used and/or analyzed during the present study are available from the corresponding author on reasonable request.

\section{Authors' contributions}

$\mathrm{CH}$ collected, analyzed and interpreted the patient data, and was a major contributor in writing the manuscript. BoZ revised the manuscript and helped to interpret the data. $\mathrm{BiZ}$ analyzed the data for the work. XGW and QPS made contributions to the acquisition of data. MC designed the present study. All authors have read and approved the final version of this manuscript.

\section{Ethics approval and consent to participate}

The current study was a retrospective study.

\section{Patient consent for publication}

Not applicable.

\section{Competing interests}

The authors declare that they have no competing interests.

\section{References}

1. Nash K, Hafeez A and Hou S: Hospital-acquired renal insufficiency. Am J Kidney Dis 39: 930-936, 2002.

2. McCullough PA, Adam A, Becker CR, Davidson C, Lameire N, Stacul F and Tumlin J; CIN Consensus Working Panel: Epidemiology and prognostic implications of contrast-induced nephropathy. Am J Cardiol 98: 5K-13K, 2006.

3. Owen RJ, Hiremath S, Myers A, Fraser-Hill M and Barrett BJ: Canadian Association of Radiologists consensus guidelines for the prevention of contrast-induced nephropathy: Update 2012. Can Assoc Radiol J 65: 96-105, 2014.

4. Tsai TT, Patel UD, Chang TI, Kennedy KF, Masoudi FA, Matheny ME, Kosiborod M, Amin AP, Messenger JC, Rumsfeld JS and Spertus JA: Contemporary incidence, predictors, and outcomes of acute kidney injury in patients undergoing percutaneous coronary interventions: Insights from the NCDR Cath-PCI registry. JACC Cardiovasc Interv 7: 1-9, 2014.

5. Gruberg L, Mehran R, Dangas G, Mintz GS, Waksman R, Kent KM, Pichard AD, Satler LF, Wu H and Leon MB: Acute renal failure requiring dialysis after percutaneous coronary interventions. Catheter Cardiovasc Interv 52: 409-416, 2001.

6. Maioli M, Toso A, Leoncini M, Gallopin M, Musilli N and Bellandi F: Persistent renal damage after contrast-induced acute kidney injury: Incidence, evolution, risk factors and prognosis. Circulation 125: 3099-3107, 2012.

7. Azzalini L, Spagnoli V and Ly HQ: Contrast-induced nephropathy: From pathophysiology to preventive strategies. Can J Cardiol 32: 247-255, 2016.

8. Rikitake Y, Kawashima S, Takeshita S, Yamashita T, Azumi H, Yasuhara M, Nishi H, Inoue N and Yokoyama M: Anti-oxidative properties of fluvastatin, an HMG-CoA reductase inhibitor, contribute to prevention of atherosclerosis in cholesterol-fed rabbits. Atherosclerosis 154: 87-96, 2001.

9. Bonetti PO, Lerman LO, Napoli C and Lerman A: Statin effects beyond lipid lowering-are they clinically relevant? Eur Heart J 24: 225-248, 2003.

10. Chello M, Goffredo C, Patti G, Candura D, Melfi R, Mastrobuoni S, Di Sciascio G and Covino E: Effects of atorvastatin on arterial endothelial function in coronary bypass surgery. Eur J Cardiothorac Surg 28: 805-810, 2005.

11. Almuti K, Rimawi R, Spevack D and Ostfeld RJ: Effects of statins beyond lipid lowering: Potential for clinical benefits. Int J Cardiol 109: 7-15, 2006.

12. QuintavalleC,Fiore D,De MiccoF, Visconti G,Focaccio A, Golia B, Ricciardelli B, Donnarumma E, Bianco A, Zabatta MA, et al: Impact of a high loading dose of atorvastatin on contrast-induced acute kidney injury. Circulation 126: 3008-3016, 2012.

13. McCullough PA, Khambatta S and Jazrawi A: Minimizing the renal toxicity of iodinated contrast. Circulation 124: 1210-1211, 2011.

14. Shehata M and Hamza M: Impact of high loading dose of atorvastatin in diabetic patients with renal dysfunction undergoing elective percutaneous coronary intervention: A randomized controlled trial. Cardiovasc Ther 33: 35-41, 2015.

15. Han Y, Zhu G, Han L, Hou F, Huang W, Liu H, Gan J, Jiang T, Li X, Wang W, et al: Short-term rosuvastatin therapy for prevention of contrast-induced acute kidney injury in patients with diabetes and chronic kidney disease. J Am Coll Cardiol 63: 62-70, 2014.

16. Leoncini M, Toso A, Maioli M, Tropeano F, Villani S and Bellandi F: Early high-dose rosuvastatin for contrast-induced nephropathy prevention in acute coronary syndrome: Results from the PRATO-ACS Study (Protective Effect of Rosuvastatin and Antiplatelet Therapy On contrast-induced acute kidney injury and myocardial damage in patients with Acute Coronary Syndrome). J Am Coll Cardiol 63: 71-79, 2014.

17. Patti G, Ricottini E, Nusca A, Colonna G, Pasceri V, D'Ambrosio A, Montinaro A and Di Sciascio G: Short-term, high-dose Atorvastatin pretreatment to prevent contrast-induced nephropathy in patients with acute coronary syndromes undergoing percutaneous coronary intervention (from the ARMYDA-CIN [atorvastatin for reduction of myocardial damage during angioplasty-contrast-induced nephropathy] trial. Am J Cardiol 108: 1-7, 2011.

18. Ozhan H, Erden I, Ordu S, Aydin M, Caglar O, Basar C, Yalcin S and Alemdar R: Efficacy of short-term high-dose atorvastatin for prevention of contrast-induced nephropathy in patients undergoing coronary angiography. Angiology 61: 711-714, 2010. 
19. Acikel S, Muderrisoglu H, Yildirir A, Aydinalp A, Sade E Bayraktar N, Bal U and Ozin B: Prevention of contrast-induced impairment of renal function by short-term or long-term statin therapy in patients undergoing elective coronary angiography. Blood Coagul Fibrinolysis 21: 750-757, 2010.

20. Su X, Xie X, Liu L, Lv J, Song F, Perkovic V and Zhang H: Comparative effectiveness of 12 treatment strategies for preventing contrast-induced acute kidney injury: A systematic review and bayesian network meta-analysis. Am J Kidney Dis 69: 69-77, 2017.

21. Levey AS, Stevens LA, Schmid CH, Zhang YL, Castro AF III, Feldman HI, Kusek JW, Eggers P, Van Lente F, Greene T, et al: A new equation to estimate glomerular filtration rate. Ann Intern Med 150: 604-612, 2009.

22. National Kidney Foundation: K/DOQI clinical practice guidelines for chronic kidney disease: Evaluation, classification, and stratification. Am J Kidney Dis 39 (Suppl 1): S1-S266, 2002.

23. Stacul F, van der Molen AJ, Reimer P, Webb JA, Thomsen HS, Morcos SK, Almén T, Aspelin P, Bellin MF, Clement O, et al: Contrast induced nephropathy: Updated ESUR Contrast Media Safety Committee guidelines. Eur Radiol 21: 2527-2541, 2011.

24. Briguori C, Manganelli F, Scarpato P, Elia PP, Golia B, Riviezzo G, Lepore S, Librera M, Villari B, Colombo A and Ricciardelli B: Acetylcysteine and contrast agent-associated nephrotoxicity. J Am Coll Cardiol 40: 298-303, 2002.

25. Horn PS, Feng L, Li Y and Pesce AJ: Effect of outliers and nonhealthy individuals on reference interval estimation. Clin Chem 47: 2137-2145, 2001

26. Jo SH, Hahn JY, Lee SY, Kim HJ, Song YB, Choi JH, Choi SH, Lee SH and Gwon HC: High-dose atorvastatin for preventing contrast-induced nephropathy in primary percutaneous coronary intervention. J Cardiovasc Med (Hagerstown) 16: 213-219, 2015.

27. Abaci O, Arat Ozkan A, Kocas C, Cetinkal G, Sukru Karaca O, Baydar O, Kaya A and Gurmen T: Impact of rosuvastatin on contrast-induced acute kidney injury in patients at high risk for nephropathy undergoing elective angiography. Am J Cardiol 115: $867-871,2015$.

28. Galal H, Nammas W and Samir A: Impact of high dose versus low dose atorvastatin on contrast induced nephropathy in diabetic patients with acute coronary syndrome undergoing early percutaneous coronary intervention. Egypt Heart J 67: 329-336, 2015.

29. Bidram P, Roghani F, Sanei H, Hedayati Z, Golabchi A, Mousavi M, Hajiannejad A, Pourheidar B, Badalabadi MM, Gharaati M, et al: Atorvastatin and prevention of contrast induced nephropathy following coronary angiography. J Res Med Sci 20: 1-6, 2015.

30. Rear R, Bell RM and Hausenloy DJ: Contrast-induced nephropathy following angiography and cardiac interventions. Heart 102 638-648, 2016

31. Attallah N, Yassine L, Musial J, Yee J and Fisher K: The potential role of statins in contrast nephropathy. Clin Nephrol 62: 273-278, 2004.

32. Khanal S, Attallah N, Smith DE, Kline-Rogers E, Share D, O'Donnell MJ and Moscucci M: Statin therapy reduces contrast-induced nephropathy: An analysis of contemporary percutaneous interventions. Am J Med 118: 843-849, 2005.

33. Patti G, Nusca A, Chello M, Pasceri V, D'Ambrosio A, Vetrovec GW and Di Sciascio G: Usefulness of statin pretreatment to prevent contrast-induced nephropathy and to improve long-term outcome in patients undergoing percutaneous coronary intervention. Am J Cardiol 101: 279-285, 2008.

34. Yoshida S, Kamihata H, Nakamura S, Senoo T, Manabe K, Motohiro M, Sugiura $\mathrm{T}$ and Iwasaka T: Prevention of contrast-induced nephropathy by chronic pravastatin treatment in patients with cardiovascular disease and renal insufficiency. J Cardiol 54: 192-198, 2009.

35. Jo SH, Koo BK, Park JS, Kang HJ, Cho YS, Kim YJ, Youn TJ, Chung WY, Chae IH, Choi DJ, et al: Prevention of radiocontrast medium-induced nephropathy using short-term high-dose simvastatin in patients with renal insufficiency undergoing coronary angiography (PROMISS) trial-a randomized controlled study. Am Heart J 155: 499 e1-e8, 2008.

36. Toso A, Maioli M, Leoncini M, Gallopin M, Tedeschi D, Micheletti C, Manzone C, Amato M and Bellandi F: Usefulness of atorvastatin $(80 \mathrm{mg})$ in prevention of contrast-induced nephropathy in patients with chronic renal disease. Am J Cardiol 105: 288-292, 2010.
37. Hall WD: Abnormalities of kidney function as a cause and a consequence of cardiovascular disease. Am J Med Sci 317: 176-182, 1999.

38. Hou W, Lv J, Perkovic V, Yang L, Zhao N, Jardine MJ, Cass A, Zhang $\mathrm{H}$ and Wang $\mathrm{H}$ : Effect of statin therapy on cardiovascular and renal outcomes in patients with chronic kidney disease: A systematic review and meta-analysis. Eur Heart J 34: 1807-1817, 2013.

39. Latif F, Kleiman NS, Cohen DJ, Pencina MJ, Yen CH, Cutlip DE, Moliterno DJ, Nassif D, Lopez JJ and Saucedo JF; EVENT Investigators: In-hospital and 1-year outcomes among percutaneous coronary intervention patients with chronic kidney disease in the era of drug-eluting stents: A report from the EVENT (Evaluation of Drug Eluting Stents and Ischemic Events) registry. JACC Cardiovasc Interv 2: 37-45, 2009

40. Natsuaki M, Furukawa Y, Morimoto T, Sakata R and Kimura T; CREDO-Kyoto PCI/CABG Registry Cohort-2 Investigators: Renal function and effect of statin therapy on cardiovascular outcomes in patients undergoing coronary revascularization (from the CREDO-Kyoto PCI/CABG Registry Cohort-2). Am J Cardiol 110: 1568-1577, 2012.

41. Dasari TW, Cohen DJ, Kleiman NS, Keyes MJ, Yen CH, Hanna EB and Saucedo JF: Statin therapy in patients with chronic kidney disease undergoing percutaneous coronary intervention (from the Evaluation of Drug Eluting Stents and Ischemic Events Registry). Am J Cardiol 113: 621-625, 2014.

42. Stone NJ, Robinson JG, Lichtenstein AH, Bairey Merz CN, Blum CB, Eckel RH, Goldberg AC, Gordon D, Levy D, Lloyd-Jones DM, et al: 2013 ACC/AHA guideline on the treatment of blood cholesterol to reduce atherosclerotic cardiovascular risk in adults: A report of the American College of Cardiology/American Heart Association Task Force on Practice Guidelines. J Am Coll Cardiol 63: 2889-2934, 2014.

43. Downs JR and O'Malley PG: Management of dyslipidemia for cardiovascular disease risk reduction: Synopsis of the 2014 U.S. Department of Veterans Affairs and U.S. Department of Defense clinical practice guideline. Ann Intern Med 163: 291-297, 2015.

44. Jacobson TA, Ito MK, Maki KC, Orringer CE, Bays HE, Jones PH, McKenney JM, Grundy SM, Gill EA, Wild RA, et al: National Lipid Association recommendations for patient-centered management of dyslipidemia: Part 1-executive summary. J Clin Lipidol 8: 473-488, 2014.

45. Catapano AL, Graham I, De Backer G, Wiklund O, Chapman MJ, Drexel H, Hoes AW, Jennings CS, Landmesser U, Pedersen TR, et al: 2016 ESC/EAS guidelines for the management of dyslipidaemias. Eur Heart J 37: 2999-3058, 2016.

46. McCullough PA, Choi JP, Feghali GA, Schussler JM, Stoler RM, Vallabahn RC and Mehta A: Contrast-induced acute kidney injury. J Am Coll Cardiol 68: 1465-1473, 2016.

47. Levine GN, Bates ER, Blankenship JC, Bailey SR, Bittl JA, Cercek B, Chambers CE, Ellis SG, Guyton RA, Hollenberg SM, et al: 2011 ACCF/AHA/SCAI Guideline for Percutaneous Coronary Intervention: Executive summary: A report of the American College of Cardiology Foundation/American Heart Association Task Force on Practice Guidelines and the Society for Cardiovascular Angiography and Interventions. Circulation 124: 2574-2609, 2011.

48. Kolh P, Windecker S, Alfonso F, Collet JP, Cremer J, Falk V, Filippatos G, Hamm C, Head SJ, Jüni P, et al: 2014 ESC/EACTS Guidelines on myocardial revascularization: The Task Force on Myocardial Revascularization of the European Society of Cardiology (ESC) and the European Association for Cardio-Thoracic Surgery (EACTS). Developed with the special contribution of the European Association of Percutaneous Cardiovascular Interventions (EAPCI). Eur J Cardiothorac Surg 46: 517-592, 2014.

49. Guitterez NV, Diaz A, Timmis GC, O'Neill WW, Stevens MA, Sandberg KR and McCullough PA: Determinants of serum creatinine trajectory in acute contrast nephropathy. J Interv Cardiol 15: 349-354, 2002.

50. Briguori C, Visconti G, Rivera NV, Focaccio A, Golia B, Giannone R, Castaldo D, De Micco F, Ricciardelli B and Colombo A: Cystatin C and contrast-induced acute kidney injury. Circulation 121: 2117-2122, 2010.

This work is licensed under a Creative Commons Attribution-NonCommercial-NoDerivatives 4.0 International (CC BY-NC-ND 4.0) License. 